Seventeen of the 41 " small goitres" occurred in 132 animals to whose food iodine was added; an incidence of 12.8 per cent. Twenty-four of the 41 " small goitres" occurred in 500 animals to whose food iodine was not added; an incidence of 4.8 per cent.

Forty-four of the 84 " slight goitres" occurred in 174 animals to whose food iodine was added; an incidence of 25.3 per cent. Forty of the 84 "slight goitres" occurred in 456 animals to whose food iodine was not added; an incidence of 8.7 per cent.

These differences are statistically significant; they indicate that the administration of iodine to the deficiently fed animals definitely favoured goitre-production.

The urinary excretion of iodine in the rats to whose deficient food iodine was added, and amongst whom goitre occurred, ranged between 85 and $158 \gamma$ per litre, except in animals fed on synthetic diets containing potassium iodide, when it averaged $200,000 \gamma$ per litre.

\section{Histological Appearances of the Goitres.}

Ninety-five of the 148 goitres were serially sectioned and cxamined microscopically. In 16 of these the post-mortem changes were so marked as to obscure the histological picture. The remaining 79 fell into the following groups, though it was not always easy to decide to which group certain specimens belonged.

(a) Nine were glands presenting no abnormality other than their "slight" increase in size.

(b) Seven were "slight" or " small" enlargements in which intense hyperaemia was the only obvious pathological change.

(c) Eight were colloid glands, all being " slight goitres." Some of them contained small keratinization cysts.

(d) Sixteen were simple hypertrophic enlargements, several appearing to merge into the lymphadenoid condition. Nine were "large" and seven were "small" goitres.

(e) Thirty-five were lymphadenoid goitres, 25 being " slight," 4 " small," and 6 "large." The characters of this type of goitre and the dietetic conditions under which it arises have previously been described in this Journal.

(f) Four were chronic hypertrophic goitres, presenting the features characteristic of this condition. All were of moderate size and all occurred in rats fed for long periods on natural diets consisting largely of whole wheat flour (atta) but poor in green vegetables and in vitamin A-bearing ingredients.

Summary.

1. A survey was made of 2,651 albino rats in a locality (Coonoor) where goitre is not endemic; 148 were found at post-mortem examination to have goitre. Of these goitres 84 were classified as " slight," 41 as " small," and 23 as "large."

2. The temperature conditions of the spring and summer months in Coonoor appeared to have been more favourable to the development of the goitres than those of the autumn and winter months.

3. The incidence of goitre was higher in females than in males.

4. Goitre was commonest in rats whose age corresponded to the period of attainment to sexual maturity.

5. Associated diseases did not appear to have exercised any appreciable influence on the incidence of goitre in these rats.

6. The goitres are not due to endemic influences.

7. The rats had no hereditary predisposition to goitre, nor were they subjected to insanitary conditions of life; both of these influences are favourable to the genesis of goitre.

8. Well-fed rats (393), living under sanitary conditions, did not develop goitre; ill-fed rats $(2,168)$, living under sanitary conditions, did. The incidence of goitre in the latter was 6.8 per cent.

9. Faulty food deficient in vitamins was the direct, or the indirect, cause of the goitres.

10. The dietetic conditions most favourable to the production of considerable goitres were provided by diets deficient in, but not wholly deveid of, certain food essentials (chiefly vitamins)

11. The administration of iodine to deficiently fed rats was definitely favourable to goitre production; its administration to rats fed on physiologically complete diets did not favour the occurrence of goitre.
12. All grades of goitre ("slight," " small," and "large") were more common in deficiently fed rats to whose food iodine was added than in those to whose food iodine was not added.

13. The urinary excretion of iodine by rats fed on deficient diets having a composition favourable to goitre production was in some experiments as low as $33 \gamma$ per' litre and in others as high as $200,000 \gamma$ per litre.

14. The histological appearances of 79 of the 148 goitres are briefly described; 44.3 per cent. were lymphadenoid goitres; 25.3 per cent. were hypertrophic goitres, some merging into the lymphadenoid condition.

15. The normal thyroid glands of Coonoor stock albino rats are, at all ages and body weights, approximately half the size of the normal thyroid glands of albino rats in the United States of America. Standards of normal thyroid weights for albino rats in one part of the world may not be applicable to albino rats in another part of the world.

\section{COKE-MEN AND BY-PRODUCTS WORKERS: THEIR COMPLAINTS AND MALADIES.}

BY

Sir THOMAS OLIVER, M.D., F.R.C.P.,

EMERITUS PROFESSOR OF MEDICINE, UNIVERSTTY OF DURHAM COLLEGE OF MEDICINE, NEWCASTLE-UPON-TYNE.

Coke, so essential for the smelting of iron, and also useful for domestic heating, is the residue left when coal has been subjected to a high temperature, away from contact with air, and which during the process of carbonization has lost several of its volatile constituents. It is a British product. Coking of coal goes back as far as 1580, when a patent was granted to John Thornborough, a Dean of York. Until recently, the carbonization was mainly effected in what are known as "bee-hive" coke ovens, rows of which can be seen from almost any railway train passing. through a mining area. When these ovens are properly. filled with coal, closed up, and heated by flues, the gas given off ignites within the ovens and fills the dome with flame. When all the gas has burned off the upper part of the dome is opened, the red-hot material inside is cooled by water spray, and is subsequently removed. As this is a wasteful method, "bee-hive" ovens have been replaced by " retort" and by "by-product" ovens. In the latter the gases are not burned off at their point of origin inside. the oven, but pass by an up-take pipe to the roof into a water-sealed trough or collecting main, whence, to quote from the Encyclopaedia Britannica, "they are drawn by exhauster's through a series of air and water-cooled condensers and scrubbers." In the first condenser, tar is deposited by the fumes passing from the overs, and in the second the ammoniacal liquor is caught This liquor, after a process of scrubbing, and with its ammonia content increased, passes on to the ammonia stills. During scrubbing with creosote or heavy tar oil, benzene is removed. When the remaining material is distilled, the tar, having yielded up burning oil, becomes pitch, and the benzene is remored from the creosote oil by steam in heated stills. To the ammoniacal liquor lime is added, and on heating this the ammonia is vaporized. The ammonia is collected, and is subsequently condensed in metallic tanks containing sulphuric acid. Ammonium sulphate-a highly valued product for manurial purposes-is thus formed. Further byproducts can still be obtained, such as toluol, naphthalene, pyridine, and motor spirit-the last, also known as benzol, being a mixture of benzene, toluene, and xylene.

The by-products obtained from coal vary with the coalfields which furnish the raw material. South Wales coal gives the largest amount of coke -80 per cent., compared with 75 per cent. from that of county Durham; but Durhan coal furnishes a larger amount of tar-3.85 per cent., compared with 2.6 per cent. from Welsh coal. The coal of South Yorkshire contains the largest amount of crude benzol-namely, 1.37 per cent.--while the coal of Durham contains 0.93 per cent., and that of South Wales 0.60 per cent. These figures are interesting, not on account of their varying commercial and economic values, but because they 
probably explain some of the differences observed in the complaints and maladies of the workers.

In a works plant those who suffer most sererely are the men working at the hydraulic mains which carry the heavy, thick fumes directly away from the ovens. Lids on the mains have to be opened, and the sluggishly moving tar is puslied on with long iron implements so that it does not block the channel. During this brief operation it is impossible for the men to avoid inhaling some of the dense fume that rises into the air, and their bare skin cannot he otherwise than adversely affected by the contact. The men whose duty it is to close the valves at the cntrance of the hrdraulic mains proximal to the ovens, to prevent any reflux from the hydraulic mains towarc's the ovens, are affected in a similar manner by the escalpe of fume. Precautionary measures have to be observed at every stage, for even at the terminal stages there are risks to health and limb. This is true in the distillation of tar. A leakage may occur owing to a structural defect in a still, and burn. may be caused if the tar ignites. The stills liave to be periodically cleaned out, and the residus, which adheres firmly to the interior, has to be remeved with a pick; this is a dusty proceeding.

In England and Wales 15,000 men are employed at coke orens and in by-products works. Although there is a National Union of Coke-men and By-products Workers, it is difficult to obtain exact data of their illnesses, as thev are members of different benefit societies. For screrai years workers in this industry have been supposed to suffer from stomach troubles to a greater extent than those following other vocations; this is indeed their most frequent and disabling complaint. There are other maladies to which they are also especially susceptible-for example, rheumatism and lumbago, skin eruptions, and warts, the latter being frequently the forerunner of ulcers which assume the characters of malignancy. Medical men residin in mining areas who attend the indisposed workmen call the stomach trouble gastritis, but there has not been, so far as I am aware, any pathological report based upon post-mortem examination clearly defining this condition, apart from cases in which cancer was found after death in the mucous membrane of the stomach of patients who were said to have had gastritis. The frequency of gastric complaints is widely admitted, particularly in the county of Durham. Symptoms develop at any age and at any period of service, in some instances three or four years after commencing work; in one patient whom I saw only six months had elapsed; the majority of the cases occur during the second or third decade of work. The symptoms complained of are pain in the region of the stomach one or two hours after taking food (although on other occasions the pain may have no relation to food), attended by flatulence, belching of sour gas, and the expulsion of acrid liquid or what is known as "water-brash." Sometimes the pain is so severe that even strong men are overcome by it. There may be marked distaste for food; on the other hand, appetite may not be impaired. The mere sight of food may cause a feeling of sickness, which ends in the vomiting of sour liquid. With the exception of a little milk no food is taken for a day or two. There are periods of remission during which the men return to work, and continue working for years with occasional digestive breakdowns. Some of them on reaching home after a day's work are drowsy, and fall asleep before taking a meal. They have a sense of fatigue which muscular wrolk does not explain; it is toxaenic. In a considerable number who present these gastric symptoms nlceration of the lining membrane of the stomach ensues, while in a smaller number the malady ends in cancer. Surgical treatment may become necessary when the symptoms of ulceration are severe, or where the ulcer has perforated the wall of the stomach. Recovery is possible, but an operation sometimes reveals not a simple ulcer, but a malignant growth. Sallow complexions are common. It is exceptional to find workmen who have spent fifteen or twenty years in the industry with the ruddy glow of health. They usually lose their colour in time. I have been struck by the light weight of many of the men. Some of them weigh only 8 st.; they readily inform the medical examiner of the weight they have lost.
The work is admittedly not havy, but it is fatiguing owing to exposure to great heat and fume.

Men employed in by-products works are liable to rashes on the skin; to warts, which, as already stated, become epitheliomata, a form of cancerous growth with ulceration, also to burns; especially is this the case among workers in tar. The rashes appear mostly on the skin of the back of the hands and forearms, usually commencing as an acute inflammation of the skin or dermatitis; the redness is accompanied by a considerable degree of itching, and by the presence of small circumscribed elevations of the skin called papules, which may become pustular and painful. Boils form, and these, when they have discharged their contents, leave a bluish flat mark. Warts are not uncommon; their presence is hazardous, for they are apt to be irritated or rubbed off and to become malignant. They appear on the back of the hands and forearms, also upon the scrotum and penis; so long as they remain simple warts they can be successfully removed, but when they become malignant the grenitalia and infected glands in the groin may have to be renoved. If the malady has progressed too far surgical treatment can give only temporary relief; yet a considerable length of life may be assured, for some of the patients $I$ have examined had been operated upon seven or eight year's previously. The warts appear in various situations. I have alluded to their presence on the genitalia. I have seen them on the brow, on the eyclids, also hanging from just inside the nostrils. They have the usual rough, uneven surface of warts generally, and they are dry and painless. The skin of the hands, which is often freckled, is hard, thickened, and disposed to crack. The "keens" thus formed are painful, and do not heal readily if work is continued. Small shot-like bodies are occasionally felt in the skin of the arms; these are not painful at first; the superjacent skin subsoquently becomes red, then dark, then it fades away, and a white mark is left. Small, red, angry-looking spots frequently appear on the chest, accompanied by itching, or there may be large, black, warty moles, especially on the back of the trunk.

During the breaking up of solid pitch no fine dust may be observed in the atmosphere a few fect above the surface of the pitch, but if the men do not wear goggles they frequently suffer from an acutely painful inflammation of the eyelids, the result either of fume or of a very fine impalpable dust. The skin of the hands and of the other parts of the body becomes reddened and itchy. These symptoms are commoner among the men who break up the pitch obtained from Durham coal than among those similarly employed in Derbyshire, which suggests that there is some inherent difference in the coal. Many tar and pitch burns become septic.

As might be expected from exposure to heat and cold, the men suffer from bronchial and other types of catarrh, and from rheumatism and lumbago. Recurrences of bronchial catarrh predispose the individual to pulmonary tuberculosis, or to a general breakdown in health in the early forties, followed by physical unfitness to resume work at the coke-ovens. I have not been able to confirm the possibility that workers are poisoned by sulphuretted hydroger, although an equally subtle form of poisoning may occur at the level of the ovens. The doors of the ovens have to be sealed as hermetically as possible. Now and then, either as a result of the expansion of the raw material during its conversion into coke, or of the displacement of a brick, there is a leakage of gas at the sides and at the foot of the doors of the ovens. Not long ago a workman emploved at the ovens was suddenly observed to fall and to become nnconscious; he was removed; a similar fate befell his surcessor. A leak had occurred, probably of carbon monoxicio gas. The leak was sealed up, but two days later, whe the coking operations had been resumed, a fresh workman was similarly overcome by gas at the same oven door.

I have recently examined twenty-three by-products workers who were under medical treatment, thirteen of these for gastritis and six for boils. It would be unreasonable to take these figures as in any way indicating the percentage of men in this industry who suffer from stomach trouble, because the men who were examined were more or less picked. At the same time I have received the 
impression from conversation with doctors in the mining areas that frequency of painful digestion and inability to take food are general symptoms.

With reference to occupational, scrotal, and penile cancer I have had the records of the Royal Victoria Infirmary, Newcastle-upon-Tyne, examined for the last two years, and I find that in 1928 fonrteen operations concerned with these types of malignant disease were performed; three of the patients were coal miners, two were gas stokers and chemical workers. Five were men aged 50 to 60 , three 60 to 70 , and three 70 to 80 . During 1929 sixteen patients were operated on for the same malady; of these eight were coal miners, one a worker in oils, and one in pitch; four were aged 50 to 60 , five 60 to 70 , and five 70 to 80 .

Snoke, fume, and excessive heat with alternating exposure to cold are the harmful agents. In such an inquiry as I have been making two forms of illness hare to be considered: there are the minor forms which cause a good deal of discomfort and temporary disablement, and which may be regarded as complaints of the workmen-for example, loss of appetite, pain after food, and vomiting, the lighter forms of skin troubles such as itchiness, boils, and "keens" on the hands; and there are the more serious forms of illness which result in cancer. The occupational operations we have been dealing with concern the manufacture of products obtained from the combustion of coal. There is a difference in regard to the manipulation of the raw material and the products obtained from it. The products obtained from coal are the more harmful. Chimney-sweaps, for example, have for long exhibited a high liability to scrotal cancer; so, too, have briquette makers, warkers in mineral oils, arsenic grinders, colour mixers, and workers in tar and its derivatives. With "pitch cancer" we have long been familiar.

In Germany tar distillation is the cause of a higher percentage of accidents than any of the other operations. Pitch breakers there suffer considerably, too, from eczema, but cases of cancer are comparatively few. In Upper Silesia, howerer, of thirty anthracene workers who had been employed for over ten years twenty-two suffered from skin eruptions, and three, with six to eight years' service, had been operated on for scrotal cancer. In France cokemen and tar workers suffer from dermatitis, but cancer is less frequently met with than in Great Britain. Cancer is infrequently observed in the United States. Dr. Thacher of the Chicago By-products Coke Corporation informs me that the ailments of the men in his employment are the same as those of the men following other trades in the district-namely, severe colds and influenza; he also states that a few of the men suffer from gastric ailments. Heart disease is a common cause of death, but, in his opinion, he does not regard this circumstance as in any way related to their occupation. During the last three years one workman died from cancer of the stomach.

Twenty years ago Sir 'Thomas Legge drew attention to the fact that blast furnace tar and pitch lo not possess the same carcinogenic properties as those of coal tar. The pitch obtained from coke ovens and gas works and used for making briquettes is said to be the cause in Great Britain of more than one-half of the notifiable cases of cancer. Drs. Bridge and Henry, in an investigation between 1920 and 1987, found that of 163 cases of cancer occurring among briquette workers, in 11 per cent. the disease was located in the scrotum, and in 71.2 per cent. in the head, arms, etc.; that out of 103 cases among tar distillers 39.8 per cent. were affected in the scrotum and 37 per cent. in the head, limbs, etc.; while in 47.3 per cent. of the men employed in gas works the discase was located in the scrotum, and in 23.6 per cent. in the head and elsewhere. Interesting information is also supplied by $\mathrm{Dr}$. Prosser White in his encyclopaedic work Occupational Diseases of the Skin, by Dr. O'Donovan, and by Dr. Scott of Broxburn in his helpful monograph upon the incidence of cancer among workers in shale oils and their derivatives.

A microscopic examination of the blood does not reveal anything absolutely definitive. This may be due to the fact that the work is carried on in the open air, and is to some extent interchangeable. In some cases the blood shows a marked deficiency of leucocytes or white corpuscles; in others the number of these cells is practically normal.
Although the atmosphere of by-product coke ovens and the conduits which carry the liquid and gaseous material away from them is redolent of fume, there are, as already stated, certain classes of workers engaged in the transit of the material whose health appears to be more severely affected than others in the industry, such as workers at the top ovens, at the hydraulic mains, the men who adjust the valves in the shafts leading into the hydraulic mains, and those who break up the solid pitchall these are liable to be adversely affected by dust, heat, and fume.

While the main incidents of the industry from a health point of riew are painful and irritating conditions of the skin, some of which exhibit a tendency to become malignant, there are also the stomach troubles to which referenco has been made; of these it may be said that the severity of the pain experienced by the workman, the physical debility that ensues, and the consequent loss of time, together form a triad of circumstances which call for recognition and carcful consideration dietetically, medicinally, and industrially.

\section{BATHS AS ARTIFICIAL CLIMATES.} The Treatment of Rheumatism in Winter.* BY

R. FORTESCUE FOX, M.D., F.R.C.P.,

President, La ligue Interationale contre le Rhumatisme; Chatrman, British Committee on Rheumatism (I.S.M.H.), 1925-29.

Since the attention of the medical profession has been directed to the chronic rheumatic diseases two lines of advance have been energetically followed, especially in England and America-namely, the investigation and treatment of the infective element in these diseases, and the use of orthopaedic methods for the rectification of posture, avoidlance of pressure upon inflamed joints, and prevention and cure of deformity. Good work on these lines has brought relief in many intractable cases, and is a welcome contribution to the campaign against rheumatism.

It is, however, possible to approach this problem from another and equally logical point of view. Five years ago an international committee on rheumatism, consisting of a small group of medical men who had long experience of rheumatic diseases in the northern countries of Europe, came into existence. They held conferences in France, Holland, Germany, Czechoslovakia, Hungary, Austria, and England. ${ }^{1}$ The committee, now an international league, has become a small connecting link between larger national bodies in these countries as well as in Russia and America. Many of their members are specializing entirely in this group of diseases; some are workers at university clinics, physicians or directors of hospital departments, of special hospitals for rheumatism, or of bath clinics in towns; others are engaged in the treatment of rheumatism on a large scale in spas and health resorts. It is clear from the various reports on rhematism issued by the Ministries of Health and Social Welfare, especially in England, that this large group of diseases has a vast incidence in cold climates, and that it is chiefly responsible for crippling and disablement in great industrial populations, not tending to shorten life, but spreading like a blight over the working period of life. The problem, apart from its medical interest, is also of great economic importance.

In the view of the league such a mass of invalidity in the best years of life demands an organized and co-operative effort for special investigation and special methods of treatment. Existing provision of this kind, especially for the treatment of early cases, is at present so fragmentary that only an insignificant fraction of the vast number of rheumatic persons can benefit by it.

The league attaches great importance to the investigation of causation. Its provisional statement ${ }^{3}$ comprises four prime factors: a cosmic or external influence*An address (abridged for publication) given to the Tunbridge Wells
Division of the British Medical Association, 